pituitary-adrenal axis is more susceptible to suppression in the evening than in the morning (Grant et al., 1965) this difference in treatment could not have led to the lower values found in the sarcoidosis patients.

Our results become comprehensible when it is realized that the recovery of adrenocortical function during the tapering off of corticosteroids is caused by gradual resumption of pituitary ACTH secretion. The rate at which these small amounts of ACTH are effective will depend on the degree of adrenocortical atrophy which had developed in earlier stages of treatment. If doses have been given which are much above the physiological range (in our case $40 \mathrm{mg}$ daily) endogenous ACTH stimulus might be entirely absent for some time, leading to severe atrophy and slow recovery. A smaller dosage (for example, 15 mg daily) will not lead to complete suppression of ACTH and the adrenal cortex will later be able to respond more readily to endogenous stimulation.

It is therefore probable that the difference we found between the sarcoidosis patients and the asthma patients can be explained by the difference in level of the initial dose of prednisone.

Some contradictory results from the literature could be explained by this theory. Robinson et al. (1962) found normal plasma fluorogenic corticosteroids in almost all patients one day after sudden withdrawal of corticosteroids. The patients, however, had not been so severely suppressed as those reported on by Graber et al. (1965), who found after more gradual withdrawal decreased corticosteroid and enhanced ACTH values.
Proof of our theory can be obtained by treating sarcoidosis patients during the initial $40-\mathrm{mg}$ prednisone period with small doses of corticotrophin and then waiting for the recovery of adrenocortical function in the withdrawal phase. Such an investigation has been started but as the same schedule has to be followed as in the former study it will be some years before results are available.

\section{References}

Bierich, J. R., Kersten, I., and Maruektad, S. (1959). Acta Endocrinologica (Kobenhavn), 31, 40.

Blumenthal, M. N., McLean, J. A., Mathews, K. P., and Sheldon, J. M. (1966). Archives of Internal Medicine, 117, 34.

Daly, J. R., Myles, A. B., Bacon, P. A., Beardwall, C. G., and Savage, O. (1967). Annals of the Rheumatic Diseases, 26, 18.

Graber, A. L., Ney, R. L., Nicholson, W. E., Island, D. P., and Liddle, G. W. (1965). Fournal of Clinical Endocrinology and Metabolism, 25, 11.

Grant, S. D. Forshman, P. H., and Di Raimondo, V. D. (1965). New England fournal of Medicine, 273, 1115.

Jakobson, T., Sundberg, M., Kotovirta, M., and Strandström, L. (1968). Acta Endocrinologica (Kobenhavn), 59, 76

Mattingly, D. (1962). Fournal of Clinical Pathology, 15, 374

Robinson, B. H. B., Mattingly, D., and Cope, C. L. (1962). British Medical fournal, 1, 1579.

Robson, A. O., and Kilborn, J. R. (1965). Thorax, 20, 93.

Sandberg, A. R., Eik-Nes, K., Migeon, C. J., and Koepf, G. F. (1957). Fournal of Laboratory and Clinical Medicine, 50, 286.

Straeten, M. van der (1964). Thesis, Ghent.

Thijssen, J. H. H., Waard, F. de, and Wiersinga, A. (1967). Lancet, 1, 814.

Westerhof, L., Ditmars, M. J. van, Kinderen, P. J. der, Thijssen, J. H. H. and Schwarz, F. (1970). British Medical fournal, 4, 534.

\title{
Diphtheria-Tetanus-Pertussis Immunization by Intradermal Jet Injection
}

\author{
J. P. STANFIELD, P. M. BRACKEN, K. M. WADDELL， D. GALL
}

British Medical fournal, 1972, 2, 197-199

\section{Summary}

An intradermal jet injector was used to administer combined diphtheria, tetanus, and pertussis (D.T.P.) vaccines to infants aged 2 to 12 months. A second dose was given one month after the first and a third six months after the second. Each dose was considerably smaller than the standard intramuscular dose. Blood samples taken one month after the third dose showed a satisfactory diphtheria and tetanus antitoxin response in all but a few cases. The antibody response to the pertussis component was not examined. Reactions were insignificant. Intradermal jet injection is proposed as a cheap, extremely rapid, and effective technique for D.T.P. immunization, especially suitable for use in remote areas where trained staff and facilities are few and many children require immunization.

Makerere University Medical School, Kampala, Uganda J. P. STANFIELD, M.D., M.R.C.P., Professor of Paediatrics and Child

P. M. BRACKEN, F.I.M.L.T., Senior Technician

Kagando Hospital, Africa Inland Mission, Uganda

K. M. WADDELL, M.B., CH.B., M.R.C.P., Medical Officer in Charge

Wellcome Research Laboratories, Beckenham, Kent

D. GALL, B.M., B.CH., D.T.M.\&H., Immunologist, Department of Aerobic Bacteriology.

\section{Introduction}

The use of the intradermal jet injector makes it possible to carry out immunization on a mass scale with the minimum of trained staff and facilities. The unreliability of some of the early models has been overcome and the instrument remains relatively cheap (about $£ 25$ ). It has been used successfully for the administration of B.C.G. vaccine (Moffat and Cook, 1970), smallpox vaccine (Heyworth, 1970), and tetanus toxoid (Rey and Triau, 1967), though recently reservations have been expressed about its use for measles immunization (S. Dauchy, personal communication, 1969; Stanfield and Bracken, 1971).

In most countries combined diphtheria, tetanus, and pertussis (D.T.P.) vaccine is now included in comprehensive immunization schedules together with poliomyelitis, B.C.G., and smallpox vaccines. The usual route of administration of D.T.P. is intramuscular, but in a controlled trial reported by Dick (1966) infants given one-third of the standard dosage of quadruple (D.T.P. + polio) vaccine by intradermal (needle) injection developed antibody levels similar to those produced by the full dosage injected intramuscularly. No constitutional upset or severe local reactions were observed. It was therefore decided to study the efficacy of D.T.P. immunization by intradermal jet injection in the field.

\section{Patients and Methods}

The trial was carried out at Kagando Hospital, with 70 beds in the care of a single doctor, situated in an isolated but heavily populated area of West Uganda. Between 1,000 and 1,500 
patients are seen regularly at the monthly children's clinic, with an attendance of 600-1,000 on any one day-a situation in which the jet injector naturally comes into its own.

A consecutive series of 443 infants (226 male and 217 female) between 2 and 12 months of age were admitted to the trial at their first visit to the clinic, when they received their first dose of D.T.P. It was intended that each child should have a second dose after an interval of one month and a third after a further interval of six months (Haire et al., 1966; Ministry of Health, 1967), but a number failed to attend for the subsequent doses and for the final blood sample one month after the third dose. Live attenuated poliomyelitis vaccine was given orally with the first dose of D.T.P., B.C.G. (intradermally) and smallpox vaccine (percutaneously) between the second and third doses, and measles vaccine (when available) with the third dose of D.T.P.

The first 259 infants (group 1) received alum-adsorbed D.T.P. vaccine intradermally, the next 79 (group 2) received unadsorbed D.T.P. vaccine intradermally, and the remaining 105 (group 3) received alum-adsorbed D.T.P. by intramuscular injection. The age distribution of the three groups and the

TABLE I-Size and Age Distribution of Groups at Various Intervals

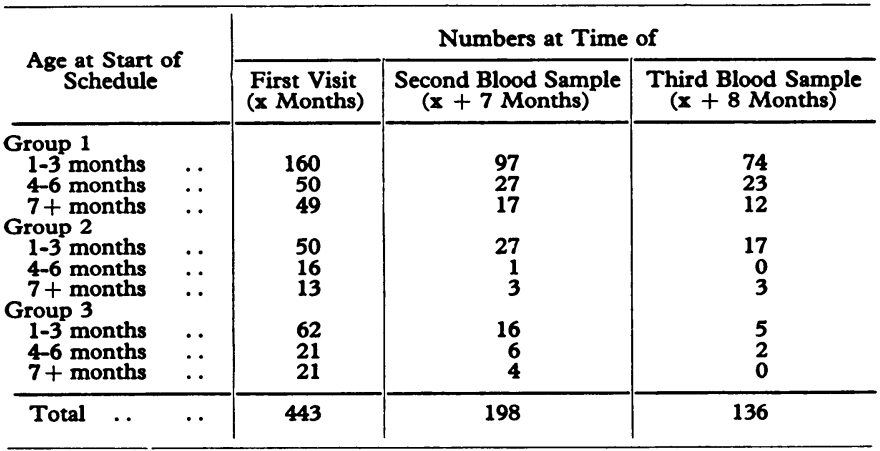

numbers remaining after each interval are shown in Table I. The adsorbed D.T.P. vaccine (Infagen) contained 20-26 Lf units of diphtheria toxoid and 10-16 Lf units of tetanus toxoid in each millilitre. The unadsorbed vaccine (Trivax) was the standard B.P. preparation containing $65 \mathrm{Lf}$ units of diphtheria toxoid and 12.5 Lf units of tetanus toxoid per millilitre. (The dosages of pertussis vaccine are irrelevant to the present study since the pertussis antibody was not measured.) The intradermal jet injectors used (Panjet Mark 5, Schuco International Ltd.) (see Fig. 1) delivered a quantity of vaccine varying

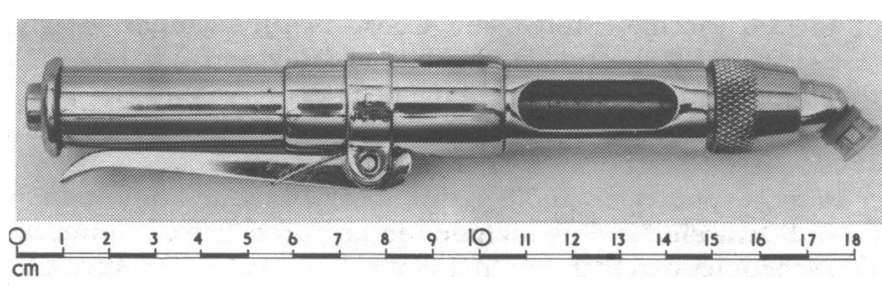

FIG. 1-The Panjet injector.

between 0.05 and $0.08 \mathrm{ml}$ at each injection. (More recent models deliver $0.1 \mathrm{ml}$.) Each intradermal dose consisted of three jet injections given into the lateral aspect of the thigh, totalling $0 \cdot 15-0.24 \mathrm{ml}$. The intramuscular dose (group 3) was $0.5 \mathrm{ml}$.

Blood for determination of antibody levels was collected at the time of the first and third doses of D.T.P. and again one month after the third dose. Each sample, consisting of $5 \mathrm{ml}$ of venous blood, was put into a sterile centrifuge tube and kept at room temperature until the end of the clinic, when it was stored at $+4^{\circ} \mathrm{C}$ and sent next day in a cold box to Makerere Medical School. There the serum was separated and stored at $-20^{\circ} \mathrm{C}$ before being sent to the Wellcome Research Laboratories in England for titration of diphtheria antitoxin by the method of
Römer and Sames (1909), as modified by Glenny and LlewellynJones (1931), and tetanus antitoxin by the method of Glenny and Stevens (1938). Pertussis agglutinins were not estimated because these may give little or no indication of protective immunity.

\section{Results}

The distributions of diphtheria and tetanus antitoxin titres in the blood samples taken (A) before immunization (excluding those cases in which no further samples were obtained), (B) six months after the second dose, and (C) one month after the third dose are set out in Tables II and III. Five children (three

TABLE II-Diphtheria Antitoxin Titre Distributions

\begin{tabular}{|c|c|c|c|c|c|c|c|c|c|}
\hline \multirow{2}{*}{$\begin{array}{c}\text { Diphtheria } \\
\text { Antitoxin } \\
\text { Titres (U/ml) }\end{array}$} & \multicolumn{3}{|c|}{ Group 1} & \multicolumn{3}{|c|}{ Group 2} & \multicolumn{3}{|c|}{ Group 3} \\
\hline & $\mathbf{A}$ & B & C & $\mathbf{A}$ & B & C & $\mathbf{A}$ & B & C \\
\hline $\begin{array}{l}<0.005 \\
0.005-0.01 \\
0 \cdot 01-0 \cdot 02 \\
0 \cdot 02-0 \cdot 05 \\
0 \cdot 05-0 \cdot 1 \\
0 \cdot 1-0 \cdot 2 \\
0 \cdot 2-0 \cdot 5 \\
0.5-1 \\
1-2 \\
2-5 \\
5-10 \\
10-20\end{array}$ & $\begin{array}{r}57 \\
11 \\
13 \\
30 \\
15 \\
6 \\
3 \\
1\end{array}$ & $\begin{array}{r}56 \\
20 \\
13 \\
14 \\
14 \\
5 \\
9 \\
3 \\
1 \\
1\end{array}$ & $\begin{array}{r}5 \\
2 \\
3 \\
10 \\
12 \\
21 \\
22 \\
16 \\
9 \\
4 \\
1\end{array}$ & $\begin{array}{l}6 \\
5 \\
5 \\
6 \\
4 \\
1\end{array}$ & $\begin{array}{l}6 \\
3 \\
4 \\
3 \\
4 \\
5 \\
1 \\
1\end{array}$ & $\begin{array}{l}2 \\
4 \\
4 \\
2 \\
3 \\
3\end{array}$ & $\begin{array}{l}9 \\
2 \\
8 \\
2 \\
1\end{array}$ & $\begin{array}{l}7 \\
1 \\
2 \\
5 \\
4 \\
3 \\
1\end{array}$ & $\begin{array}{l}2 \\
3 \\
1\end{array}$ \\
\hline No. of subjects & $136^{*}$ & 136 & 105 & $27^{*}$ & 27 & 18 & $23 *$ & 23 & 6 \\
\hline
\end{tabular}

$\mathbf{A}=$ Pre-immunization sample. $\mathbf{B}=$ Six months after second dose. $\mathbf{C}=$ One month after third dose.

- Subjects from whom no subsequent samples were obtained are excluded.

TABLE III-Tetanus Antitoxin Titre Distributions

\begin{tabular}{|c|c|c|c|c|c|c|c|c|c|}
\hline \multirow{2}{*}{$\begin{array}{c}\text { Tetanus } \\
\text { Antitoxin } \\
\text { Titres }(\mathrm{U} / \mathrm{ml})\end{array}$} & \multicolumn{3}{|c|}{ Group 1} & \multicolumn{3}{|c|}{ Group 2} & \multicolumn{3}{|c|}{ Group 3} \\
\hline & $\mathbf{A}$ & B & C & A & B & C & A & B & C \\
\hline $\begin{array}{l}<0 \cdot 02 \\
0 \cdot 02-0.05 \\
0 \cdot 05-0 \cdot 1 \\
0 \cdot 1-0 \cdot 2 \\
0 \cdot 2-0.5 \\
0 \cdot 5-1 \\
1-2 \\
2-5 \\
5-10 \\
10-20\end{array}$ & 140 & $\begin{array}{r}84 \\
13 \\
19 \\
15 \\
6 \\
2 \\
\\
\\
1\end{array}$ & $\begin{array}{r}5 \\
4 \\
3 \\
3 \\
4 \\
7 \\
29 \\
22 \\
16 \\
15 \\
4\end{array}$ & 28 & $\begin{array}{r}6 \\
10 \\
3 \\
8 \\
1\end{array}$ & $\begin{array}{l}3 \\
2 \\
6 \\
5 \\
1\end{array}$ & 25 & $\begin{array}{r}5 \\
3 \\
2 \\
10 \\
4 \\
1\end{array}$ & $\begin{array}{l}2 \\
4 \\
1\end{array}$ \\
\hline Total & $140^{*}$ & 140 & 109 & $28^{*}$ & 28 & 17 & $25^{\circ}$ & 25 & 7 \\
\hline
\end{tabular}

$\mathbf{A}=$ Pre-immunization sample. $\mathbf{B}=$ Six months after second dose. $\mathbf{C}=$ One Subjects from whom

from group 2 and one each from groups 1 and 3) have been eliminated from the final analysis. They were found to have measurable tetanus antitoxin titres (over $0.5 \mathrm{unit} / \mathrm{ml}$ ) in their pre-immunization serum samples and this was taken to indicate previous exposure to D.T.P. immunization (four were over 8 months of age). All three groups showed, in general, satisfactory responses to the diphtheria and tetanus components by the time of the third bleeding, one month after the third dose. There were, however, some individuals who responded poorly to both diphtheria and tetanus after the intradermal adsorbed D.T.P. (group 1). The number of patients in group 3 from whom a third blood sample was obtained was too small for valid comparisons to be made; at the time of the second sample, when such comparisons were possible, the antibody titres were poor and inadequate in all three groups.

On statistical analysis the only significant difference between the results of the immunization procedures was found in the tetanus antitoxin titres at the second bleeding, when the mean response in group 1 was poorer than in groups 2 and $3(P<$ 0.001 ). A possible explanation is that owing to a tendency for the adsorbed triple vaccine to froth when administered by the intradermal injector, only a proportion of the dose was injected. This frothing occurs also with measles vaccine and is thought to 
be the main reason why measles immunization given by intradermal jet injection is so uncertain. It should also be borne in mind that the vaccines were of different manufacture. The effect of nutritional status on antibody response was checked by examination of the infants' weight charts. Most of the children received at least their first two doses of vaccine before the age of weaning and therefore before the period of "weight faltering" and early malnutrition. Of the 109 children in group 1 from whom the third blood sample was obtained, 50 were below $80 \%$ and four below $60 \%$ of the expected weight for age on one or more visits (usually the last one or two). There was no significant diminution of antibody response in these children.

Immediate reactions to the intradermal injections could not be documented, but few were reported at the next visit. One of us (K.M.W.) has adopted this technique of immunization as a standard procedure with adsorbed D.T.P. and has never had any severe untoward effects reported to him. Small indurated marks about 5-7 $\mathrm{mm}$ in diameter were observed one month after each dose but had disappeared entirely in three to four months. In one underweight child an ulcer about $15 \mathrm{~mm}$ in diameter developed at the site of one of the injections one month later. Unfortunately, no record was made of this and the type of vaccine used is therefore not known. The lesion had healed by the next visit.

\section{Discussion}

These results are encouraging. They indicate that intradermal D.T.P. in reduced dosage can stimulate antibody production to levels similar to those obtained with the standard intramuscular schedule when three doses are given. The use of the intradermal injector enables a very rapid rate of immunization to be maintained, the necessity of sterilizing needles and syringes during the clinic being eliminated. The method is therefore very useful in the field, where a presterilized instrument can be filled with vaccine sufficient for 20 children. The reservoir can be refilled with one syringe and needle as necessary.

General reactions to the intradermal injection of D.T.P. may be less frequent than those after intramuscular injection, as is the case with T.A.B. It would seem likely that the plain vaccine is less reactive locally than the alum-adsorbed vaccine, which has the additional disadvantage of a tendency to froth. To date, hepatitis has not been found to be associated with the use of jet injectors. Although occasionally a spot of blood was noticed on the rim of the nozzle of the instrument, the jet of vaccine does not touch this rim.

The importance of the good results obtained with this method must be judged against the background of large numbers of unimmunized children attending a clinic staffed by a single doctor with few, mostly unskilled, locally trained assistants and meagre facilities. The method is now in use in one or two clinics in Uganda, but further monitoring of the safety and reliability of the technique is still required. It might well be the method of choice for routine immunization clinics in any part of the world.

We would like to thank the Chief Medical Officer, Ministry of Health, Uganda, for permission to publish this material. One of us (P.M.B.) was in receipt of a grant from the Wellcome Trust for the study of modifications of immunization schedules applicable to developing countries. We acknowledge with thanks the generosity of the Wellcome Trust and the encouragement of Dr. J. A. Dudgeon and Professor G. Dick.

The assistance of the staff of Kagando Hospital was willingly and cheerfully given and the close liaison developed during the conduct of the trial between ourselves and the hospital was relinquished most reluctantly.

\section{References}

Dick, G. (1966). Canadian Public Health fournal, 57, 435.

Glenny, A. T., and Llewellyn-Jones, M. (1931). Fournal of Pathology and Bacteriology, 34, 143.

Glenny, A. T., and Stevens, M. F. (1938). Fournal of the Royal Army Medical

Haire, M., Dane, D. S., Dick, G., Briggs, E. M., and Connor, T. J. (1966) fournal of Hygiene, 64, 485 .

Heyworth, B. (1970). Fournal of Tropical Pediatrics and African Child Health, 16,17 .

Ministry of Health (1967). U.K. Circular letter on Immunizations in Childhood, Chief Medical Officer, CMO/20/67.

Moffat, M., and Cook, R. (1970). Report on the Ankole BCG Dermojet Trial mimeo. Department of Paediatrics, P.O. Box 7072, Kampala, Uganda.

Rey, M., and Triau, R. (1967). Bulletin de la Société Médicale d'Afrique Noire de Langue Francaise, 12, 230.

Römer, P. H., and Sames, T. (1909). Zeitschrift für Immunitätsforschung und experimentelle Therapie, 3,344

Stanfield, J. P., and Bracken, P. M. (1971). Transactions of the Royal Society of Tropical Medicine and Hygiene, 65, 620.

\section{Excretion of Urinary Casts after the Administration of Diuretics}

\section{P. R. IMHOF， J. HUSHAK， G. SCHUMANN， P. DUKOR， J. WAGNER， H. M. KELLER}

British Medical fournal, 1972, 2, 199-202

\section{Summary}

The administration of ethacrynic acid and frusemide to healthy volunteers was regularly followed by the excretion of hyaline casts, without any concomitant proteinuria. Hydrochlorothiazide and chlorthalidone did not themselves induce cylindruria but augmented that provoked by acidifying agents. It was shown by the

Biological Research Laboratories of the Pharmaceuticals Division of Ciba-Geigy Limited, Basle, Switzerland

P. R. IMHOF, M.D., Head, Human Pharmacology Laboratories

J. HUSHAK, M.D., Clinical Associate, Human Pharmacology Laboratories G. SCHUMANN, PH.D., Senior Biologist, Immunology Laboratories P. DUKOR, M.D., Head, Immunology Laboratories

J. WAGNER, PH.D., Assistant Professor, Senior Chemist, Biochemical Pharmacology

District Hospital, Belp, Switzerland

H. M. KELLER, M.D., Assistant Professor, Physician-in-Chief indirect immunofluorescence method that the casts were composed of uromucoid (Tamm-Horsfall mucoprotein), which is always present in the urine, usually in solution, and originates predominantly from the tubule cells of the ascending limb of Henle's loop. The urinary excretion of Tamm-Horsfall mucoprotein was not increased after the administration of ethacrynic acid. This mucoprotein is precipitated and forms aggregates when the concentration of electrolytes increases and when the pH of the urine declines. The casts that appear in the urine after strenuous physical exertion are of essentially the same composition. Casts produced by patients with kidney diseases, on the other hand, contain various protein fractions derived from the blood as well as mucoprotein. Cylindruria occurring during diuretic therapy and physical exertion is of no pathological significance, and the diagnostic value of byaline casts is very much limited if their exact composition cannot be determined. 